\title{
Globe
}

Revue internationale d'études québécoises

\section{Yvan Lamonde et Jonathan Livernois, Papineau : erreur sur la personne, Montréal, Boréal, 2012}

\section{Marc Chevrier}

Volume 16, numéro 1, 2013

URI : https://id.erudit.org/iderudit/1018186ar

DOI : https://doi.org/10.7202/1018186ar

Aller au sommaire du numéro

Éditeur(s)

Globe, Revue internationale d'études québécoises

ISSN

1481-5869 (imprimé)

1923-8231 (numérique)

Découvrir la revue

Citer ce compte rendu

Chevrier, M. (2013). Compte rendu de [Yvan Lamonde et Jonathan Livernois, Papineau : erreur sur la personne, Montréal, Boréal, 2012]. Globe, 16(1),

208-211. https://doi.org/10.7202/1018186ar d'utilisation que vous pouvez consulter en ligne.

https://apropos.erudit.org/fr/usagers/politique-dutilisation/ 


\section{Yvan Lamonde et Jonathan Livernois \\ Papineau : erreur sur la personne, Montréal, Boréal, 2012.}

Il est rare que se publie au Québec, sur la scène restreinte de l'essai historique, un ouvrage à ce point percutant que le lecteur, étonné de ce qu'il vient de lire, se pose la question : "Comment se fait-il que personne n'ait vu une si grossière méprise ?» C'est l'impression que laisse l'essai incisif et rafrâchissant signé par l'historien chevronné Yvan Lamonde et l'essayiste et professeur de littérature Jonathan Livernois. À lire cet ouvrage, on découvre l'ampleur et la persistance têtue d'une erreur, qui dépasse en fait la seule personne de Louis-Joseph Papineau et qui touche fondamentalement à la nature des idées politiques qu'ont défendues les Patriotes dans leur combat contre la monarchie coloniale britannique. Voici l'erreur: les livres d'histoire, les personnages les plus fameux ou universitaires les plus en vue, de Lord Durham jusqu’à Jocelyn Létourneau, répètent jusqu’à plus soif que les Patriotes réclamaient le gouvernement responsable à l'anglaise, soit un cabinet de ministres nommés par le gouverneur parmi les partis en chambre et possédant la confiance des députés. Au fond, Papineau et ses braves patriotes auraient préparé la voie au gouvernement responsable gracieusement accordé par Lord Elgin à Lafontaine et Baldwin en 1848, à cette voie médiane modérée, pétrie de collaboration et de conciliation, qui se serait tramée dès 1830 et de laquelle les rébellions de 1837-1838, telle une infidélité dans l'histoire d'un couple monogame, auraient momentanément dévié.

L'erreur est si profondément ancrée que même Jacques Parizeau, ainsi que le rappellent Lamonde et Livernois en introduction, lors de son discours donné à l'Assemblée nationale en septembre 1995 sur la question référendaire, dit de Papineau qu' « [e]n réclamant le gouvernement responsable pour la colonie québécoise, il voulait ce qu'on appelle aujourd'hui la souveraineté ». Double méprise, soutiennent les auteurs, puisque Papineau, un adversaire indéfectible du gouvernement responsable, ne fut pas, si l'on croit ses positions en faveur de l'annexion du Bas-Canada aux États-Unis, voire de la création d'une grande fédération continentale " colombienne » dont le BasCanada deviendrait l'un des États, un défenseur de l'indépendance séparée de la colonie. En somme, c'est travestir les faits et la pensée de Papineau que d'en faire tantôt un précurseur de la responsabilité ministérielle et de la bonne entente collaborationniste, tantôt le père de l'indépendance nationale québécoise, au sens que revêtait cette idée à partir des années 1960. En 
démontant les fausses continuités fabriquées par l'historiographie dominante et les façonneurs d'opinion, notamment que 1848 serait l'aboutissement de 1837, les auteurs mettent en lumière la continuité de la pensée politique de Papineau, resté fidèle à lui-même dans son combat, en insistant sur l'aspect proprement républicain de cette pensée, irréductiblement attachée à la défense des libertés du peuple et de l'extension de la démocratie à tous les pouvoirs. Les auteurs montrent bien l'inconséquence de penser que Papineau pût vouloir conduire à la liberté un peuple soumis au joug colonial par le moyen d'un régime de responsabilité ministérielle dont le gouverneur continuerait d'être l'obligé de Londres et de nommer le conseil législatif. Et après l'union de 1840, accepter le gouvernement responsable, c'était pour Papineau renoncer au surplus à la représentation proportionnelle de la population au parlement.

Les auteurs consacrent deux chapitres à la fabrication de l'erreur, dont l'origine remonte au fameux diagnostic posé par Lord Durham, qui expliquait entre autres les rébellions de 1837-1838 au Bas-Canada par une lutte pour l'obtention d'un exécutif responsable, ce qui lui permit, en inventant un tel problème, de justifier les conclusions finales de son rapport, soit l'union des deux colonies coiffée de l'octroi de la responsabilité ministérielle. Les auteurs reconnaissent qu'il y eut certes des défenseurs à l'époque d'un exécutif responsable, mais en établissant que, dans l'ensemble, cette revendication fut étrangère aux Patriotes, qui misaient sur l'élection des deux chambres pour relayer la voix du peuple au pouvoir. On voit comment la vérité historique a vite été sacrifiée à la nécessité de composer un récit édifiant des valeureux perdants de 1837-1838, soulignant la continuité des victoires du Canada français, fortifié par le réformisme conciliateur.

Le démontage de l'erreur se corse quand les auteurs s'amusent à déconstruire les généreuses interprétations postérieures à celle de Lionel Groux, qui entonnent la même ritournelle. John Saul, Jocelyn Létourneau et André Pratte ont chacun droit à leur examen clinique. Ces trois ont en commun, comme l'a souligné Éric Bédard cité par les auteurs, de vouloir " contrecarrer le grand récit historique des Québécois, qui serait trop axé sur la victimisation, les défaites politiques et le ressentiment à l'égard des Anglais». Tous trois exaltent une canadianité modérée peu soucieuse de la vérité historique et qui remplacerait, au musée des idoles, Papineau par Lafontaine. On sent que le duo d'auteurs s'irrite des inventions lénifiantes du «métahistorien » Létourneau ou d'un éditorialiste pressé de monumentaliser sa vision de «l'histoire tronquée... et mythique du Canada». 
L'énormité de la méprise surprend certes, mais sans effacer la perplexité du lecteur. Si les Patriotes ne voulaient pas du gouvernement responsable, que réclamaient-ils donc? L'ouvrage nous livre en fait des réponses partielles, en raison sans doute des limites de départ de l'exercice auquel les auteurs se sont prêtés. Ainsi, outre l'élection du Conseil législatif, on ne voit pas précisément en quoi consistait réellement le système de gouvernement préconisé par les Patriotes. Si les auteurs soulignent l'origine américaine du républicanisme des Patriotes, ils nous disent peu de choses sur la pratique gouvernementale américaine dont ils auraient pu s'inspirer, un détour obligé, me semble-t-il, pour bien saisir le débat politique de l'époque. Or les Patriotes avaient à leur disposition trois sources américaines: 1) la pratique du gouvernement colonial dans les colonies américaines avant l'indépendance - leur assemblée était monocamérale et certaines élisaient le gouverneur ; 2) la pratique gouvernementale dans les États américains après 1787; 3) la pratique du gouvernement fédéral américain. Que visaient les Patriotes? Une synthèse de ces trois éléments appliquée au contexte bas-canadien? Une enquête sur la formation du gouvernement responsable au Royaume-Uni aurait été fort utile; les historiens ont tendance à considérer le gouvernement ministériel comme une pratique parfaitement établie dans la métropole au début du XIX ${ }^{e}$ siècle, coulant de source, alors que ce n'est qu'après l'élargissement électoral de 1832 et la tentative ratée du roi Guillaume IV d'imposer un cabinet qu'elle devient effectivement rodée. Les auteurs reprennent les thèses de Lamonde sur l'américanité des Patriotes, au risque toutefois de mettre de côté l'influence du républicanisme anglais théorisé par les historiens de l'école de Cambridge et auquel les Patriotes empruntent une bonne partie de leur vocabulaire pour dénoncer la corruption coloniale. Du reste, Papineau, sans être un Danton ou un Lafayette, avait une vaste culture politique perméable au républicanisme français, ce que, à trop mettre l'accent sur l'américanité de Papineau, on risque d'oublier. Enfin, à trop voir l'arbre, si majestueux soit-il, on oublie la forêt. Papineau ne résume pas à lui seul tout le républicanisme patriote, qui a connu de nombreux porte-étendards, comme Louis-Antoine Dessaulles - que Lamonde a déjà portraituré en libéral anticlérical -, lequel, comme Papineau, avait vu dans l'annexion le moyen d'une émancipation démocratique, tandis que les promesses de la démocratie américaine n'étaient pas encore obscurcies par la guerre civile.

L'ouvrage se termine sur le constat du triste délabrement où se trouve la conscience historique des Québécois, dont la mémoire des Patriotes s'est fixée sur des objets et des «symboles déracinés». Se souvenir équivaut à se dispenser d'une véritable réflexion sur son passé, déplorent Lamonde et 
Livernois, qui en appellent ainsi à la naissance d'"une véritable conscience démocratique et historique ", capable de "dédramatiser la défaite ou l'échec" et qui, au lieu de lire l'histoire du pays à l'aune de «faux sentiments de continuité ", débusque les heurts et les inaccomplissements dont cette histoire a été marquée, comme "l'achoppement des idées républicaines». On ne peut que souscrire à cet appel, qui est un magnifique plaidoyer pour une véritable histoire politique au Québec, libre, au service de la curiosité, de l'intelligence et de la rigueur, et non de la doxographie des censeurs et des penseurs officiels qui ont appliqué sur notre histoire nationale tant de vernis épais, aujourd'hui si difficiles à décaper. Pour l'instant, cette histoire politique est à l'image du tombeau de Papineau à Montebello, comme le signalent en épilogue Lamonde et Livernois: "un lieu mal entretenu, couvert de mauvaises herbes", aux accès verrouillés.

Marc Chevrier

Université du Québec à Montréal

\section{Magaly Brodeur \\ Vice et corruption à Montréal, 1892-1970, Québec, Presses de l'Université du Québec, 2011.}

Boursière de la Fondation Trudeau (2009-2012) et gagnante du concours Ça mérite d'être reconnu! (2012), Magaly Brodeur s'impose graduellement comme spécialiste de l'histoire des politiques publiques au Québec. Ses travaux sont reconnus par ses pairs, ce qui nous invite par le fait même à un regard plus critique. De son mémoire de maîtrise en histoire ( $« \mathrm{La}$ ville de Montréal et la question des jeux de hasard et d'argent (1930-1970) : crime organisé, corruption et financement municipal»), l'auteure a tiré cet ouvrage, intitulé Vice et corruption à Montréal, 1892-1970, pour lequel elle a remporté le prix Chercheurs auteurs de la relève 2010 des Presses de l'Université du Québec. Comme le titre et la périodisation l'indiquent, l'auteure a voulu élargir sa perspective et embrasser plus large. L'idée-force du mémoire est toutefois restée la même, et ce, malgré les changements majeurs apportés au manuscrit, ce qui apporte son lot de problèmes.

Dans cet ouvrage, Brodeur veut nous plonger dans «l'époque de la prohibition des jeux de hasard et d'argent au Canada", comme nous 